\title{
Gastric linitis plastica due to metastatic lobular breast carcinoma
}

\author{
Hugh J FreEman, MD, URve KuUsK, MD, JenNifER DAVIS, MD
}

HJ FreEMAN, U KUUSK, J DAVIS. Gastric linitis plastica due to metastatic lobular breast carcinoma. Can J Gastroenterol 1993;7(1):55-57. A 35-yearold female with previously diagnosed lobular breast carcinoma presented with clinical radiographic and endoscopic features of a diffuse gastric infiltrative process. Multiple gastric biopsies revealed characteristic histological features of a metastatic lobular breast carcinoma. In patients with a history of breast carcinoma, distinction between primary and secondary gastric malignancy is important as treatment options may differ substantially. Recognition that the scirrhous changes in the stomach are due to metastatic breast carcinoma, particularly of the lobular histological type, may lead to further palliative pharmacologic therapy that could benefit the patient and improve survival.

Key Words: Cancer of the stomach, Chemotherapy, Gastric cancer, Linitis plastica, Lobular breast carcinoma, Signet ring cell

\section{Linite plastique gastrique attribuable au cancer lobulaire métastatique du sein}

RÉSUMÉ: Une femme de 35 ans, chez qui un cancer lobulaire du sein avait déjà été diagnostiqué, se présente avec des signes cliniques, radiologiques et endoscopiques d'un processus infiltrant diffus au niveau de l'estomac. De nombeuses biopsies gastriques ont révélé des caractéristiques histologiques typiques du cancer lobulaire métastatique du sein. Chez les patientes qui ont des antécédents de cancer du sein, la distinction entre cancer de l'estomac primaire et secondaire est importante, puisque les choix thérapeutiques en dépendent considérablement. L'identification d'un changement squirrheux au niveau de l'estomac est dû à la présence d'un cancer du sein métatastique particulièrement de type histologique lobulaire et peut permettre un traitement pharmacologique palliatif qui bénéficierait à la patiente et améliorerait ainsi ses chances de survie.

Departments of Medicine (Gastroenterology), Surgery and Pathology, University Hospital and University of British Columbia, Vancouver, British Columbia

Correspondence and reprints: Dr Hugh Freeman, Head, Gastroenterology, ACU F-137. University Hospital (UBC Site), 2211 Wesbrook Mall, Vancouver, British Columbia V6T IW5. Telephone (604) $822-7216$ or $822-7235$

Received for publication January 9, 1992. Accepted July 15, 1992
B REAST CARCINOMA IS THE MOST common malignancy in women and metastases occur frequently, particularly to lymph nodes, bones, lung, liver and brain. Although previously considered to be rare (1) gastric metastasis from breast carcinoma has been increasingly recorded (2-7). Radiologic and pathological patterns of gastric metastatic disease include: microscopic or macroscopic disease without detectable radiographic change; solitary or multiple nodules, often with ulceration, that may appear as a radiographic filling defect; and diffuse gastric infiltration that simulates more typical linitis plastica of the stomach. In these patients, the characteristic histologic features of lobular carcinoma may be present (8). Recognition of this histologic subgroup and its ability to mimic primary gastric linitis plastica may be important because of the recent developments in the role of palliative chemotherapy and hormonal treatment in improving quality of life and survival of patients with metastatic breast carcinoma.

\section{CASE PRESENTATION}

A 35-year-old female was referred in March 1991 for investigation of a seven-month history of progressive nausea, vomiting and a $16 \mathrm{~kg}$ weight 


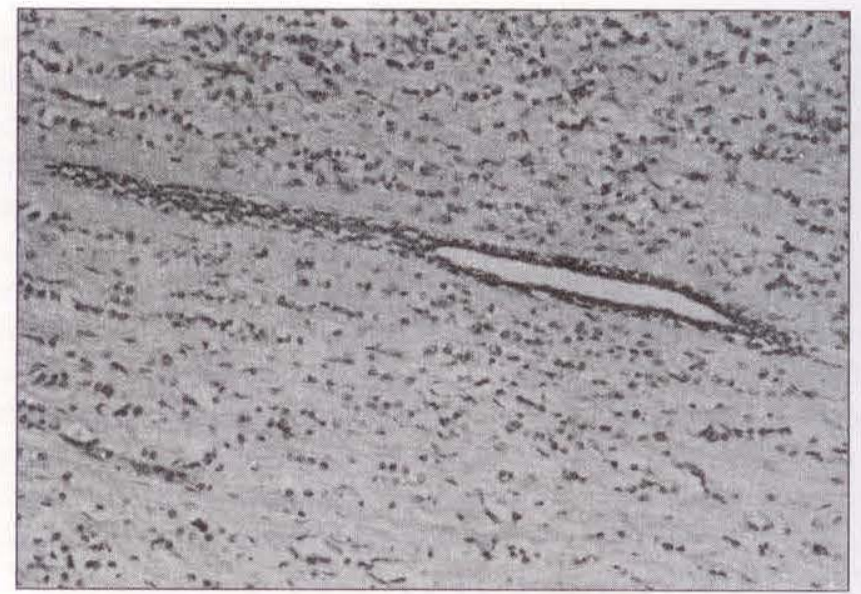

Figure 1) Section of breast carcinoma obtained at mastectomy in 1988. Cords of infiltrating neoplastic cells are observed. (Hematoxylin and eosin $x 115)$

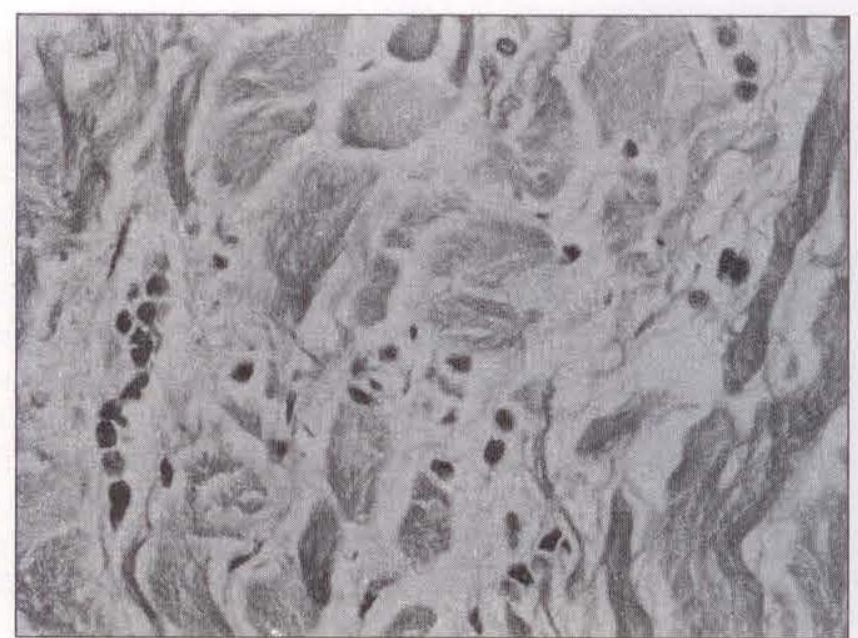

Figure 3) Section from chest wall obtained in March 1991. Cords of infiltrating neoplastic cells arranged in single file formation are evident. (Hematoxylin and eosin $\times 320$ )

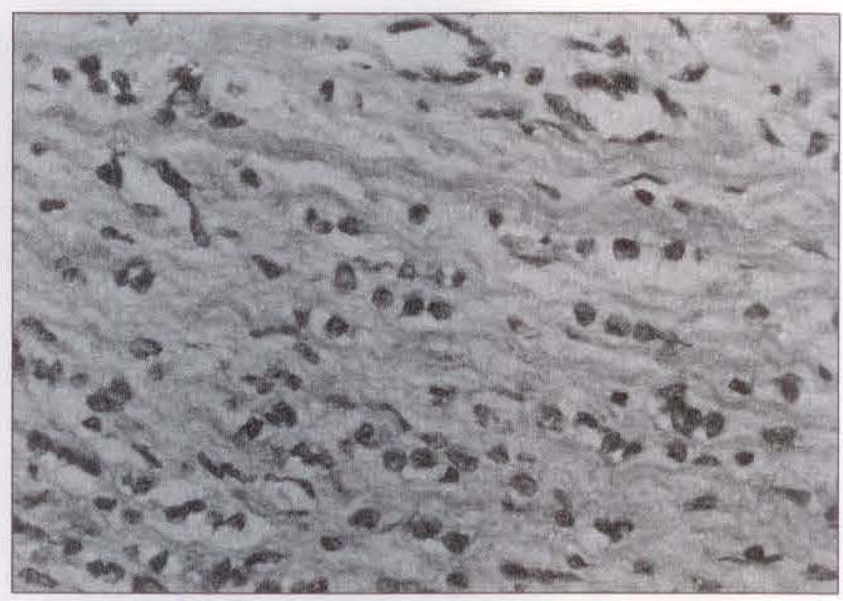

Figure 2) Section of breast carcinoma in Figure 1 showing poorly differentiated breast carcinoma cells arranged in single file formation. (Hematoxylin and eosin $\times 290$ )

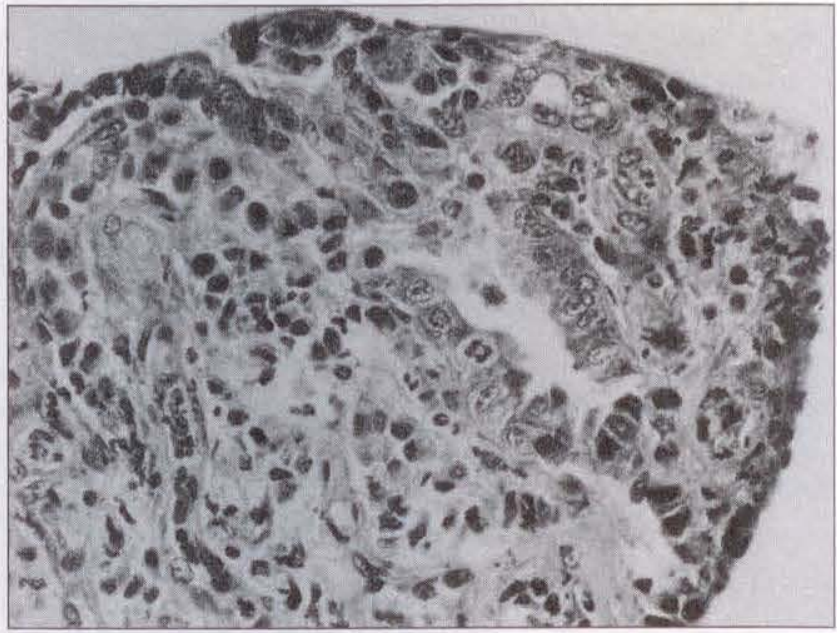

Figure 4) Section from gastric mucosa obtained by endoscopic biopsy in March 1991. Infiltrating neoplastic breast carcinoma cells arranged in single file formation are present in the lamina propria. (Hematoxylin and $\operatorname{eosin} \times 320$ ) loss. She complained of dysphagia, particularly for solids, and emesis of virtually undigested food almost immediately following a meal. Recent investigations done in a community hospital prior to referral included chest radiographs, abdominal ultrasound, upper gastrointestinal barium and endoscopic studies; all were reported to be normal. Past history included a modified radical mastectomy in 1988 for a lobular carcinoma of the left breast (Figures 1,2); at that time, lymph nodes were negative for metastases. Reconstructive breast surgery, was completed in May 1989; however, localized recurrence of breast carcinoma was detected in December 1989 and was treated with. radiotherapy.
Examination at referral in March 1991 revealed a cachectic woman with a left mastectomy scar and a left breast prosthesis but no lymphadenopathy. Abdominal examination was normal. An erythematous area on the left chest wall was biopsied and showed infiltrating lobular breast carcinoma (Figure 3 ). Laboratory studies including hemogram, multichannel blood chemistry analysis and abdominal ultrasound were normal. Abdominal computerized tomography suggested enlarged paraaortic lymph nodes and possible gastric wall thickening. Upper gastrointestinal endoscopy revealed narrowing and rigidity of the gastroesophageal junction; the patient experienced discomfort with air insufflation of the stomach. Gastric fundic, body and antral mucosa were abnormally thickened, typical of a diffuse infiltrating process. Multiple endoscopic gastric mucosal biopsies revealed the lamina propria to be expanded by an infiltrate composed of malignant cells with histologic characteristics similar to the previously defined lobular infiltrating breast carcinoma (Figure 4); the gastric epithelium was normal and intestinal metaplasia was not present. A barium swallow revealed a thickened and rigid stomach characteristic of the typical radiologic features of gastric linitis plas. tica (Figure 5). A feeding jejunostomy was inserted because of her inability to eat and a course of chemotherapy was initiated using 5-fluorouracil, doxoru- 
bicin and cyclophosphamide. She had a good clinical response with a $10 \mathrm{~kg}$ increase in weight and resolution of chest wall disease. By July 1991, she was able to tolerate a normal diet and her jejunostomy tube was removed. She completed her eighth and final course of chemotherapy in August 1991. She has been able to maintain her original weight on a normal diet since that time and repeat barium radiographic studies in December 1991 revealed evidence for improved gastric wall distensibility (Figure 6). At this time, she is clinically well on tamoxifen alone.

\section{DISCUSSION}

Breast carcinoma is the most common malignancy in women and metastatic involvement of distant sites especially lymph nodes, bone, liver, lung and brain - is frequent. Previous reports, however, have also regularly documented the occasional patient with breast carcinoma and gastric metastases (1-8). Although some autopsy series $(5,6)$ have reported an incidence as high as $15 \%$, definitive premortem diagnosis of metastatic breast carcinoma with gastroscopic mucosal biopsy is much less common. This may reflect limited clinical recognition that gastric linitis plastica in a female, especially with a previously diagnosed breast carcinoma, can be due to metastatic breast carcinoma. In addition, distinct histological features of breast carcinoma may be difficult to define, especially if the characteristic 'single file' adenocarcinoma cells of the lobular variety of breast carcinoma are difficult to recognize (8); this is not a typical microscopic feature of gastric cancer. In addition, smaller biopsies obtained at the time of endoscopic evalua-

\section{REFERENCES}

1. Warren S, Witham EM. Studies on tumor metastasis. 2. The distribution of metastases in cancer of the breast. Surg Gynecol Obstet 1933;57:81-5.

2. Asch MJ, Wiedel PD, Habif DV. Gastrointestinal metastases from carcinoma of the breast: Autopsy study and 18 cases requiring operative intervention. Arch Surg 1968;96:840-3.

3. Choi SH, Sheehan FR, Pickren JW. Metastatic involvement of the

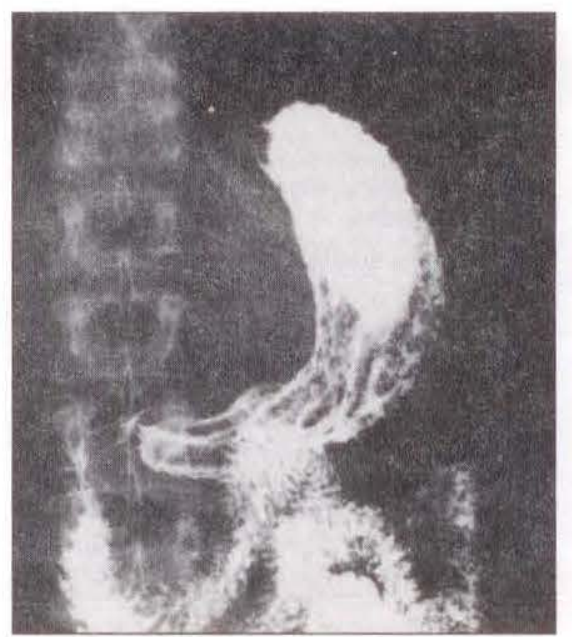

Figure 5) Barium radiographic study done in March 1991 showing thickened and rigid gastric folds characteristic of the typical radiologic features described for gastric linitis plastica

tion may not permit differentiation of a primary gastric carcinoma from a metastatic lesion. Specific diagnosis, however, may be critical as evaluation for chemotherapy and/or hormonal treatment may be worthwhile particularly if metastatic breast carcinoma is present. Diagnosis of metastatic lobular carcinoma of the breast may be aided by definition of hormonal receptors, breast specific antigens or other markers, such as cytoplasmic globules (9).

Although a number of reports have described linitis plastica due to metastatic carcinoma of the breast, the histologic subtype has been only occasionally detailed. Choi et al (3) described the primary histological features in six cases as "poorly differentiated rows of small anaplastic cells" and the diffuse involvement in these cases as distinguished from "medium differentiated carcinomas" with nodular or ulcerative gastric involvement.

stomach by breast cancer. Cancer 1964;17:791-7.

4. Cifuentes N, Pickren JW. Metastases from carcinoma of mammary gland: An autopsy study. J Surg Oncol 1979;11:193-205.

5. Graham WP III, Goldman L. Gastrointestinal metastases from carcinoma of the breast. Ann Surg 1964:59:477-80.

6. Hartmann WP, Sherlock P. Gastroduodenal metastases from carcinoma of the breast: An adrenal steroid-induced

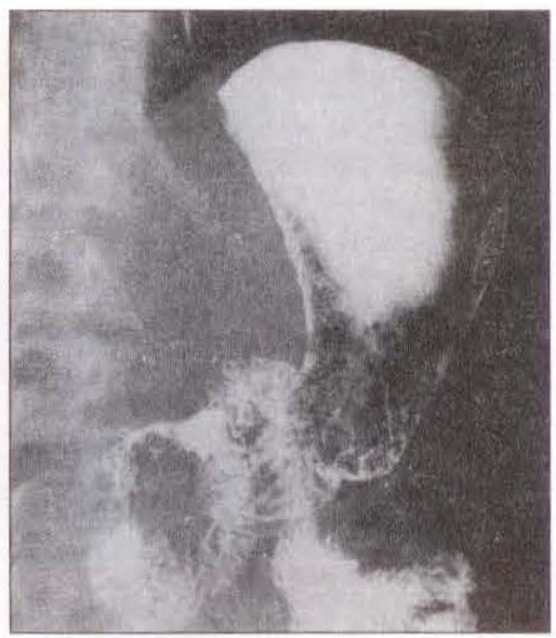

Figure 6) Barium radiographic study done December 1991 showing improved distensibility of gastric folds following chemotherapy

Cormier et al (8) described 31 patients with lobular breast carcinoma and linitis plastica due to metastases seen during a 30-year interval at the Mayo Clinic; of these, 14 had gastric involvement alone or concurrent with other metastases, similar to the current patient, providing evidence of tumour dissemination. Linitis plastica due to gastric metastases from primary ductal carcinoma was not observed; this type of breast carcinoma metastases appears to cause discrete nodules in the stomach, sometimes with mucosal ulceration or serosal implants as the dominant feature (8). As chemotherapeutic and hormonal treatment regimens have significantly improved survival in patients with metastatic breast carcinoma, recognition and accurate diagnosis of the protean presentations of disseminated disease, particularly in the gastrointestinal tract, may be critical to successful management.

phenomenon. Cancer 1961;14:426-31.

7. Menuck LS, Amberg JR. Metastatic disease involving the stomach.

Am J Dig Dis 1975;20:903-13.

8. Cormier WJ, Gaffey TA, Welch JM, Welch JS, Edmonson JH. Linitis plastica caused by metastatic lobular carcinoma of the breast. Mayo Clinic Proc 1980;55:747-53.

9. Andersen JA, Vendelboe ML. Cytoplasmic mucous globules in lobular carcinoma in situ. Am J Surg Pathol 1981;5:251-5. 


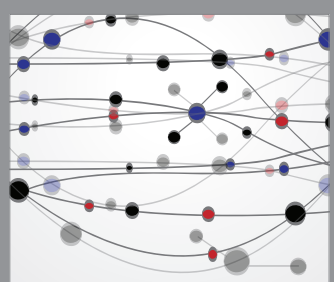

The Scientific World Journal
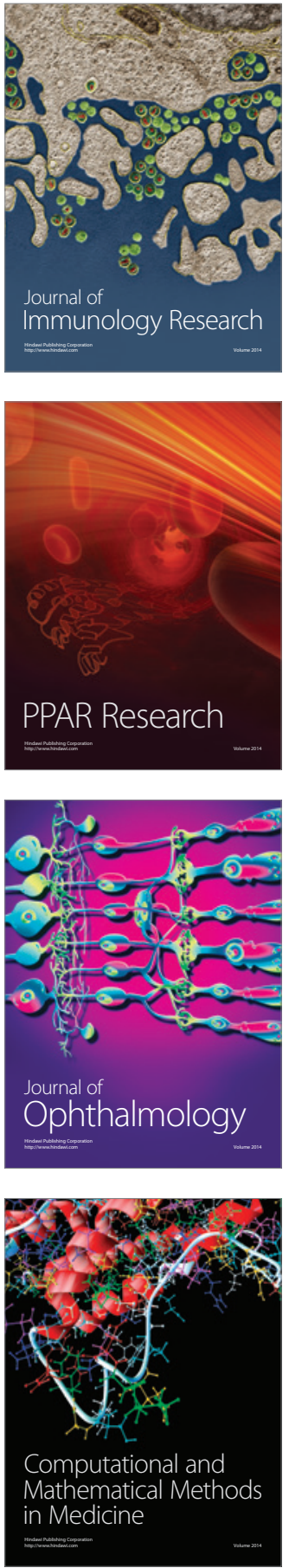

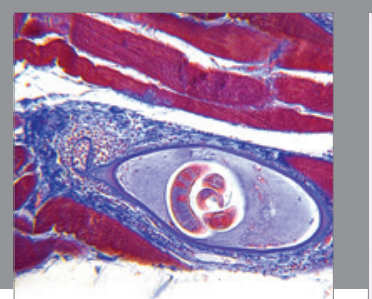

Gastroenterology Research and Practice

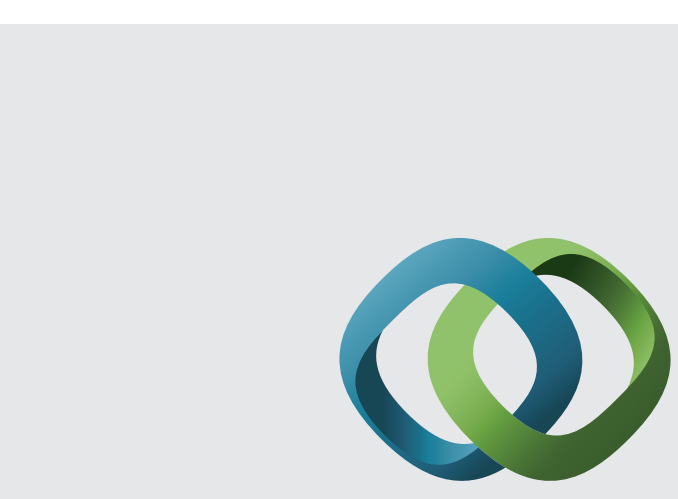

\section{Hindawi}

Submit your manuscripts at

http://www.hindawi.com
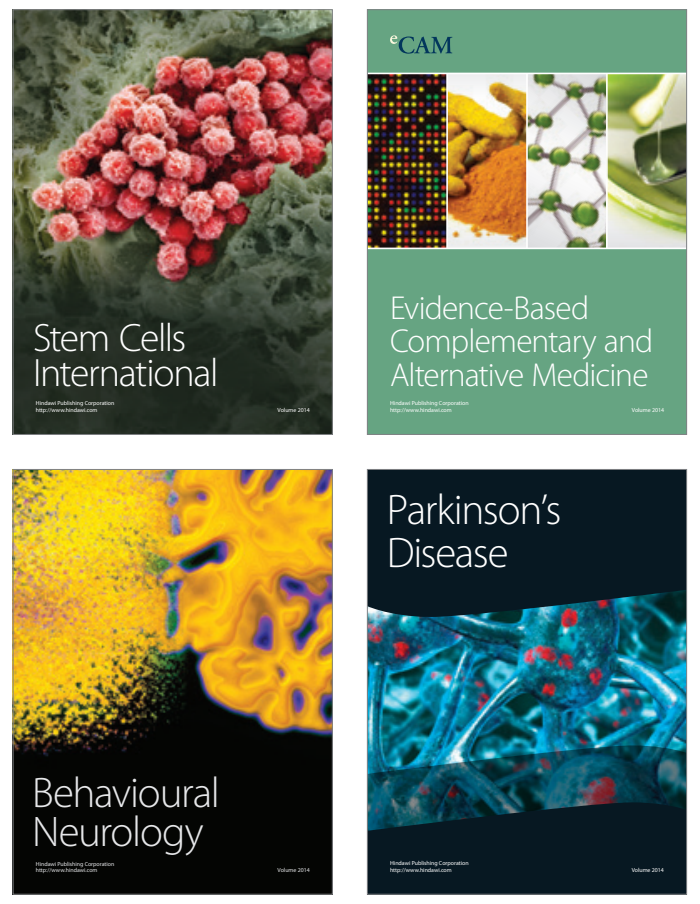
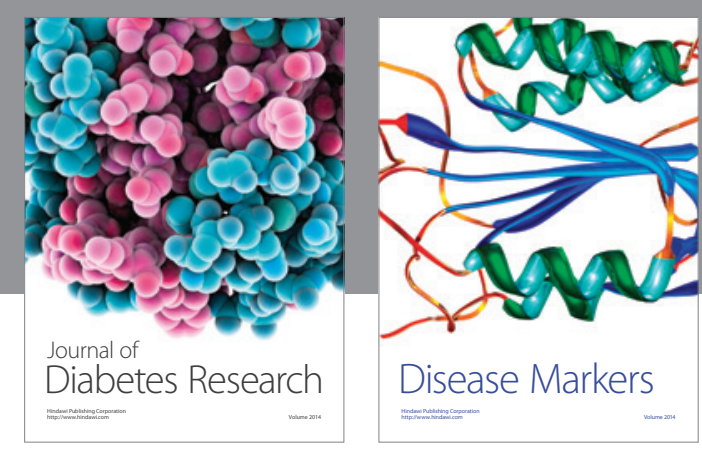

Disease Markers
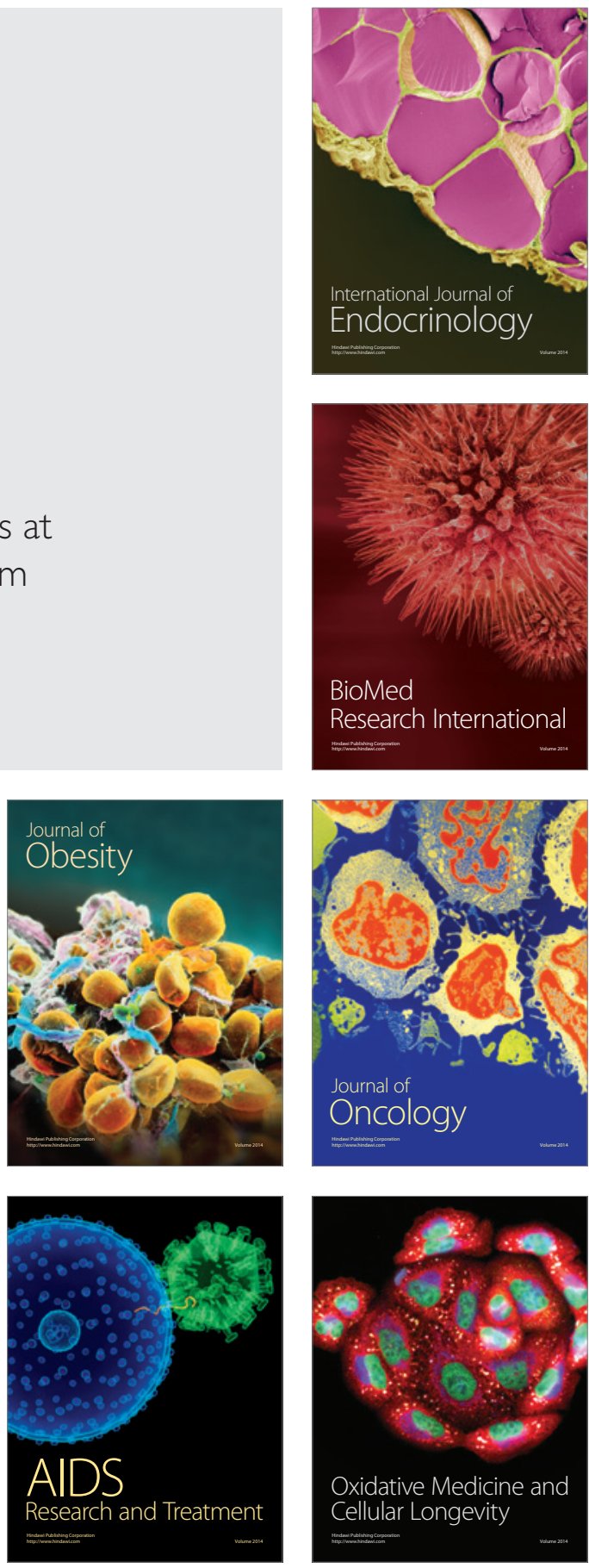